\title{
Hydrochemical Characteristics and Formation Mechanism of Strontium-Rich Groundwater in Shijiazhuang, North China Plain
}

\author{
Duo Li, ${ }^{1}$ Shuang Gan, ${ }^{1}$ Junfeng Li, ${ }^{2}$ Zihan Dong, ${ }^{1}$ Qi Long, ${ }^{1}$ Shuwei Qiu, ${ }^{1}$ Yahong Zhou $\mathbb{D}^{1},{ }^{1}$ \\ and Changyu Lu ${ }^{1}$ \\ ${ }^{1}$ School of Water Resources and Environment, Hebei Province Key Laboratory of Sustained \\ Utilization and Development of Water Resources, Hebei Province Collaborative Innovation Center for Sustainable \\ Utilization of Water Resources and Optimization of Industrial Structure, Hebei GEO University, Shijiazhuang 050031, China \\ ${ }^{2}$ Hebei Institute of Hydrological Engineering Geology Investigation, Shijiazhuang 050031, China
}

Correspondence should be addressed to Yahong Zhou; zhyh327@163.com

Received 11 January 2021; Revised 16 February 2021; Accepted 13 March 2021; Published 25 March 2021

Academic Editor: Chengcheng Li

Copyright $(2021$ Duo Li et al. This is an open access article distributed under the Creative Commons Attribution License, which permits unrestricted use, distribution, and reproduction in any medium, provided the original work is properly cited.

\begin{abstract}
Strontium is a kind of trace element. Groundwater containing strontium is called mineral water when its content reaches a level that is beneficial for human physiology. Some groundwater resources in Shijiazhuang are rich in strontium. In this study, groundwater samples collected from 103 sites were studied for the hydrochemical characteristics of strontium and its formation mechanism in the groundwater system in Shijiazhuang City. The methods of source provenance analysis, factor correlation analysis, and runoff condition analysis were carried out in the study. The results showed that the content of strontium in eastern Shijiazhuang is higher than $0.229 \mathrm{mg} / \mathrm{L}$, with a maximum content of $1.942 \mathrm{mg} / \mathrm{L}$. The source of strontium is the dissolution of strontium-containing minerals in carbonate rock, sheet hemp rock, clastic rock, and granite in the Taihang Mountain area of the Hutuo River Basin. Strontium is positively correlated with total dissolved solids, bicarbonate, calcium magnesium, and free carbon dioxide. The erosion ability of groundwater strengthens the dissolution of strontium, and the geochemical action is mainly due to the dissolution. The enrichment and distribution of strontium are related to the conditions of groundwater runoff. Areas with good runoff conditions and strong mining are low in strontium, while areas with poor runoff conditions have high strontium content.
\end{abstract}

\section{Introduction}

Strontium is an alkaline-earth element, and its average abundance in the continental crust is $350 \mathrm{ppm}$ [1]. Its elemental abundance varies among different types of magmatic rocks and sedimentary rocks. Among carbonate rocks, gypsum and phosphorous block rocks have the highest abundance of Sr. There are more than 30 kinds of strontiumbearing minerals in nature. The most important one is strontianite [2]. The strontium content of mineral water containing strontium is more than $0.2 \mathrm{mg} / \mathrm{L}$. Strontium mineral water, metasilicate mineral water, and carbonated mineral water are the main types of natural mineral water used for drinking in China. Strontium mineral water is distributed all over the country and is mainly found in Jilin, Shanxi, Jiangsu, Sichuan, and other regions. The function of strontium in the human body is mainly related to the formation of bones, and it is a normal component of human bones and teeth. It is also related to the function and structure of blood vessels. Excessive sodium in the body can cause hypertension and cardiovascular diseases, while strontium can reduce the absorption of sodium in the human body. Therefore, strontium has the effect of preventing these diseases [3]. Thus, the exploitation of natural strontium mineral water from available sources is of great importance. 
Shijiazhuang is a border area between the Shanxi Block and the sags of the Bohai Basin. On the western part of Shijiazhuang are the Taihang Mountains, with an altitude of about $1000 \mathrm{~m}$. The eastern part of Shijiazhuang is the alluvial proluvial plain of the Taihang Mountains, which is generally $30-100 \mathrm{~m}$ above sea level. Natural mineral water is widely distributed in Shijiazhuang and its surrounding areas, in which the indexes of strontium are up to the standard. This means the natural mineral water in these areas has enormous potential economic value. However, due to the lack of reasonable and unified planning for the development, utilization, and protection of mineral water resources in this area, such as unlicensed disordered mining and mixed layer mining, a large number of valuable resources are used for industrial, agricultural, and urban domestic water, which cannot be used with high quality, and the large-scale exploitation of groundwater leads to various environmental problems such as aquifer drainage and groundwater pollution, resulting in the waste of resources and environmental pollution. The rich and valuable mineral water resources in the study area have not been well developed, utilized, and protected. Therefore, the distribution characteristics, sources, migration, and enrichment trends and other hydrochemical characteristics of strontium in the study area should be analyzed $[4,5]$. It can provide scientific basis for the development and protection of natural mineral water resources and give full play to the value of mineral water $[6,7]$. The distribution, enrichment, and migration of strontium in groundwater are affected by many factors. At present, scholars have studied the influence of silty clay, groundwater, and various factors on the adsorption of $\mathrm{Sr}^{2+}$. For example, the effects of contact time, solid-liquid ratio, and tracer concentration on the adsorption ratio of strontium on silty clay were studied by the static indicator method [8]. Through static experiments, the relationships among strontium adsorption and conventional anions and cations in groundwater were obtained [9-11]. The adsorption ability of strontium ions in the soil is related to lithology [12, 13], calcium ions, and other single ions $[14,15]$. At the same time, loess [16] and different wetting media [17] also affect the migration ability of strontium ions. With the rapid development of the national economy, the demand for groundwater quality has forced us to analyze the influencing factors of groundwater quality in more detail. For example, the analysis of effects of carbon dioxide [18], groundwater system [19-21], groundwater chemical environment [22-24], and geological conditions [25] on strontium ions, the analysis of elements in mineral water $[26,27]$, and the evaluation of natural mineral water [28] have been reported in recent years. These previous research results have laid a solid foundation for the development of this study.

The main objectives of this research are to (1) characterize the depth, lithology, water abundance, and other aspects of the aquifers in the study area; (2) assess the distribution characteristics of strontium in groundwater; (3) analyze the correlation between strontium and other components; and (4) investigate the origin of $\mathrm{Sr}$ in groundwater. This study is designed to support local decision makers in decision making related to sustainable development and utilization of groundwater mineral water.

\section{Materials and Methods}

2.1. Field Studies-Study Area. The study area is a part of the piedmont alluvial fan area in front of the Taihang Mountains. It is situated at latitude $37^{\circ} 58^{\prime} 30^{\prime \prime} \mathrm{N} \sim 38^{\circ} 08^{\prime} 45^{\prime \prime} \mathrm{N}$ and longitude $114^{\circ} 25^{\prime} 30^{\prime \prime} \mathrm{E} \sim 114^{\circ} 48^{\prime} 35^{\prime \prime} \mathrm{E}$ in the southeastern part of Hebei covering an area of $650 \mathrm{~km}^{2}$. The geological formation comprises a thick sequence of Quaternary deposits of mid-Pleistocene to recent age, which is composed of unconsolidated sand, silt, clay and kankar in various proportions. The climate in this region belongs to the warm temperate semihumid semiarid continental monsoon climate zone. It is characterized by dry and windy spring, hot and rainy summer, cool autumn, and cold winter. The average temperature ranges from 11 to $23^{\circ}$. The total annual rainfall is $493.3 \mathrm{~mm}$. Corn and wheat are the major crops of the district.

2.2. Collection of Groundwater Samples. A total of 44 shallow groundwater samples and 29 deep groundwater samples were collected from the study area (Figure 1). The sample collection, processing, and storage methods were undertaken as per the standard procedures stipulated by the ministry of water resources in China to ensure data quality and consistency. In the study, the following physical and chemical parameters were analyzed: total dissolved solids (TDS), major cations $\left(\mathrm{Mg}^{2+}, \mathrm{Ca}^{2+}\right.$, and $\left.\mathrm{Sr}^{2+}\right)$, major anions $\left(\mathrm{Cl}^{-}, \mathrm{SO}_{4}^{2-}\right.$, and $\left.\mathrm{HCO}_{3}^{-}\right)$, and trace compounds such as free carbon dioxide $\left(\mathrm{CO}_{2}\right)$ and metasilicate $\left(\mathrm{H}_{2} \mathrm{SiO}_{3}\right) \cdot \mathrm{Ca}^{2+}$ and $\mathrm{Mg}^{2+}$ concentrations were determined using titration. The conductivity analyzer was used to measure EC and TDS. $\mathrm{Sr}^{2+}$ concentration was measured by ICP-AES.

\section{Results and Discussion}

3.1. The Characteristics of Water-Containing Media in the Study Area. The study area is located in the eastern part of Shijiazhuang, at the top and middle of the alluvial fan of the Hutuo River, covering $650 \mathrm{~km}^{2}$. According to the type of the water-containing medium, geological age, and other factors, the fourth system in the study area is divided into shallow aquifer and deep aquifer.

The shallow aquifer is formed by $\mathrm{Q}_{3}$ and $\mathrm{Q}_{4}$, called a submerged aquifer. The western part of the study area is affected by the exploitation of groundwater for many years. The areas of Zhengding Zhuhe-Xi Zhaotong-Century ParkJia village west of the first line have been dewatering. The water table of water-bearing layers in the eastern area is buried at the depth of $40 \mathrm{~m}$ to $90 \mathrm{~m}$. The thickness of the aquifer is $20 \mathrm{~m}$ to $50 \mathrm{~m}$. The main rocks are gravel, gravel containing, medium sand, water conducting, and water rich, with a permeability coefficient of 100 to $200 \mathrm{~m} / \mathrm{d}$. The amount of water per unit is generally between 30 and $80 \mathrm{~m}^{3} / \mathrm{h} \cdot \mathrm{m}$. 


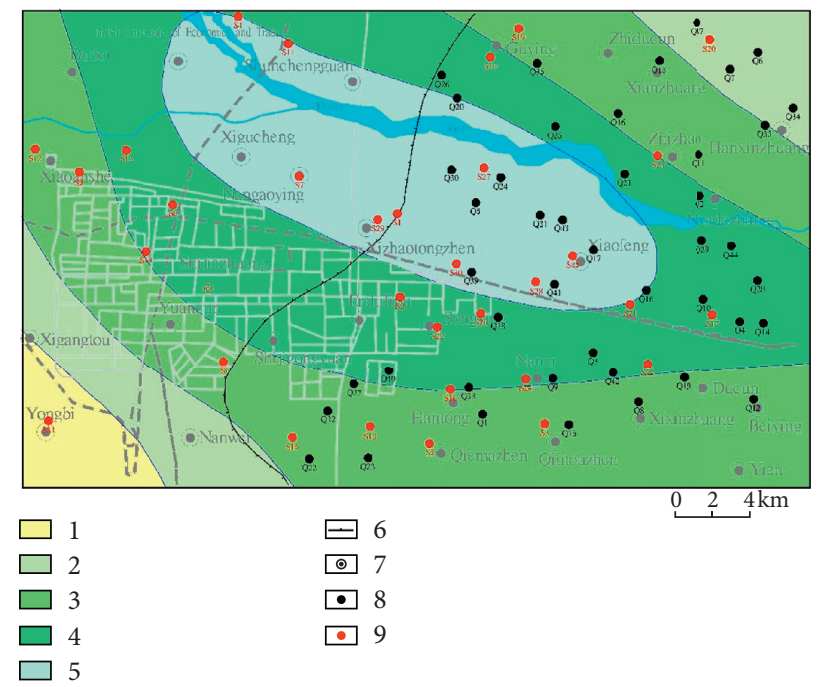

FIGURE 1: Study area and sampling locations: (1) water abundance of groundwater $<10 \mathrm{~m}^{3} / \mathrm{h} \cdot \mathrm{m}$; (2) water abundance of groundwater is between 10 and $30 \mathrm{~m}^{3} / \mathrm{h} \cdot \mathrm{m} ; 3$ ) water abundance of groundwater is between 30 and $50 \mathrm{~m}^{3} / \mathrm{h} \cdot \mathrm{m}$; (4) water abundance of groundwater is between 50 and $70 \mathrm{~m}^{3} / \mathrm{h} \cdot \mathrm{m}$; (5) water abundance of groundwater $>70 \mathrm{~m}^{3} / \mathrm{h} \cdot \mathrm{m} ;$ (6) boundary of the drainage area; (7) villages; (8) sampling points of shallow groundwater; and (9) sampling points of deep groundwater.

The deep aquifer is formed by $\mathrm{Q}_{1}$ and $\mathrm{Q}_{2}$. The western part of the Sanlitun-Xi Zhaotong-Remain village is phreatic water. There is no stable aquiclude between it and the overlying shallow aquifer. The west of the line is confined water. The water table is buried between $80 \mathrm{~m}$ and $480 \mathrm{~m}$. The thickness of the aquifer is 45 to $180 \mathrm{~m}$. The main rock is gravel pebble, gravel-containing coarse sand, water conducting, and water rich, with a permeability coefficient of 30 to $130 \mathrm{~m} / \mathrm{d}$. The amount of water per unit is generally 40 to $110 \mathrm{~m}^{3} / \mathrm{h} \cdot \mathrm{m}$.

\subsection{Distribution Characteristics of Strontium in Groundwater.} Statistical summary of various parameters of strontium measured in groundwater is presented in Table 1. The abundance of $\mathrm{Sr}$ in the shallow groundwater ranges from $0.396 \mathrm{mg} / \mathrm{L} \sim 1.942 \mathrm{mg} / \mathrm{L}$, and that in the deep groundwater ranges from $0.229 \mathrm{mg} / \mathrm{L} \sim 1.837 \mathrm{mg} / \mathrm{L}$. The mode and standard deviation of strontium concentration in shallow and deep groundwater are, respectively, $1.092 \mathrm{mg} / \mathrm{L}, 0.368$ and $0.460 \mathrm{mg} / \mathrm{L}, 0.326$, with the average values of $1.023 \mathrm{mg} / \mathrm{L}$ and $0.771 \mathrm{mg} / \mathrm{L}$. Significantly, the average strontium concentration in shallow groundwater is higher than that in deep groundwater [29]. Histograms are drawn according to the frequency of strontium values in shallow and deep groundwater (Figure 2). As can be seen from the figure, the concentration of $\mathrm{Sr}$ in the shallow layer and deep layer presents a normal distribution and is mainly concentrated around the mean values of 1.023 and 0.771 .

The contour map of Sr (Figure 3) is drawn according to the strontium concentration values at the sampling points. As shown in Figure 3, the surface distribution of strontium in shallow and deep groundwater has the same characteristics: the strontium content in groundwater varies in different parts of the alluvial-diluvial fan. The content of strontium increases gradually from the top to the middle parts and both sides of the bottom of the alluvial fan. The low-value zone of strontium content is located in the fan axis of Shijiazhuang City-High-tech zone-the oil refinery, and the high-value zone is located in the north and south. The $\mathrm{Sr}$ content in the south is higher than that in the north.

\subsection{Correlation with Other Ions}

3.3.1. Correlation between Strontium and Free $\mathrm{CO}_{2}$. The abundance of $\mathrm{Sr}$ in the geological environment determines the strontium content in groundwater. High strontium abundance is conducive to the enrichment of strontium. Carbonate formations are the most suitable for Sr enrichment, and the clastic environments are the second most favorable. The content of strontium is abundant in the carbonate aquifer. $\mathrm{SrCO}_{3}$ is a constituent mineral of carbonate salts and is insoluble in groundwater environment. Contact with corrosive water increases the solubility of the mineral. The lithology of the Taihang Mountains in the west of Shijiazhuang is mainly carbonate rock and gneisses which contain a large amount of strontium minerals, such as $\mathrm{SrCO}_{3}$ and $\mathrm{SrSO}_{4}$. The formation of $\mathrm{Sr}$ mineral water occurs because the Sr-containing minerals are easily dissolved in water. Sr in groundwater in the study zone is derived from the dissolution of carbonate minerals. Hence, the concentration of strontium has a certain correlation with the concentration of free $\mathrm{CO}_{2}$. The relationship between the concentration of $\mathrm{Sr}$ and free $\mathrm{CO}_{2}$ in shallow and deep groundwater is shown in Figure 4. The results verify that there is a positive correlation between $\mathrm{Sr}$ and free $\mathrm{CO}_{2}$. Specifically, the strontium content in groundwater rises gradually with the increase in the content of free carbon dioxide. 
TABLE 1: Mathematical statistics of strontium in shallow and deep groundwater.

\begin{tabular}{lcc}
\hline The concentration of $\mathrm{Sr}$ & Shallow aquifer & Deep aquifer \\
\hline Mean value & 1.023 & 0.771 \\
Median & 1.001 & 0.747 \\
Mode & 1.092 & 0.460 \\
Standard deviation & 0.368 & 0.326 \\
Variance & 0.136 & 0.128 \\
Range & 1.546 & 1.608 \\
Min & 0.396 & 0.229 \\
Max & 1.942 & 1.837 \\
\hline
\end{tabular}

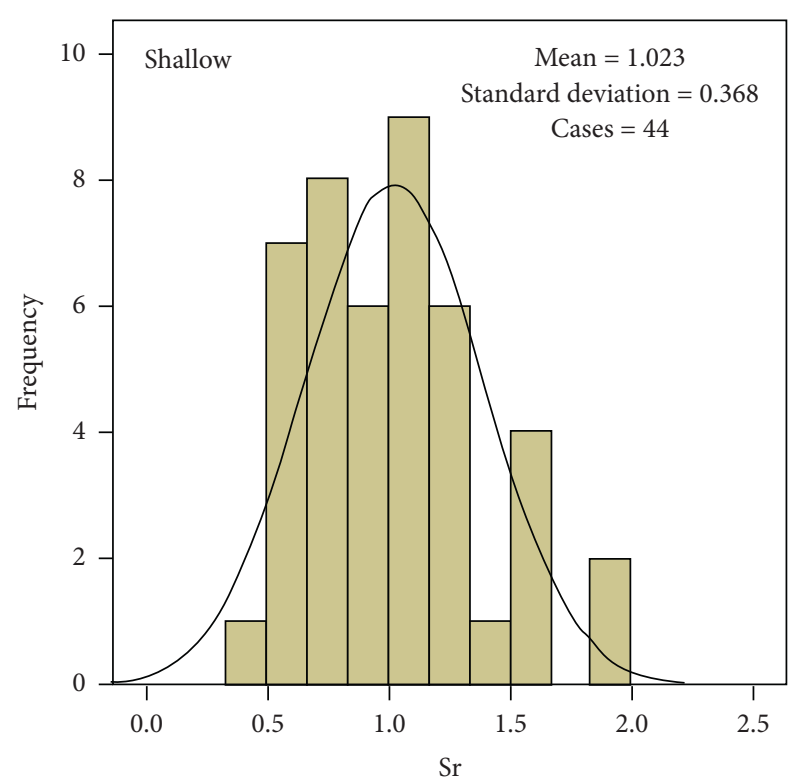

(a)

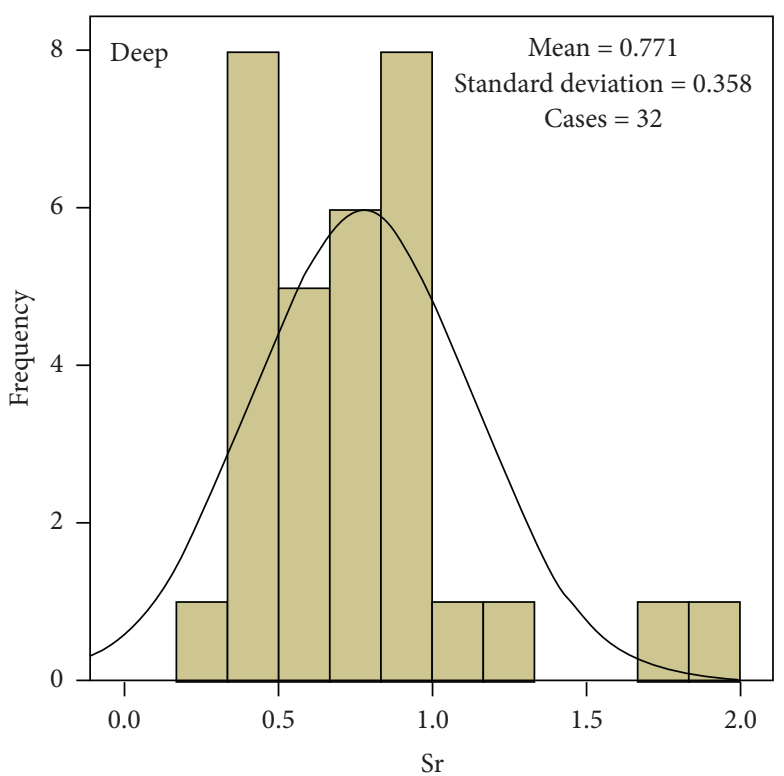

(b)

FIgURE 2: Frequency histogram of strontium concentration in shallow and deep groundwater.

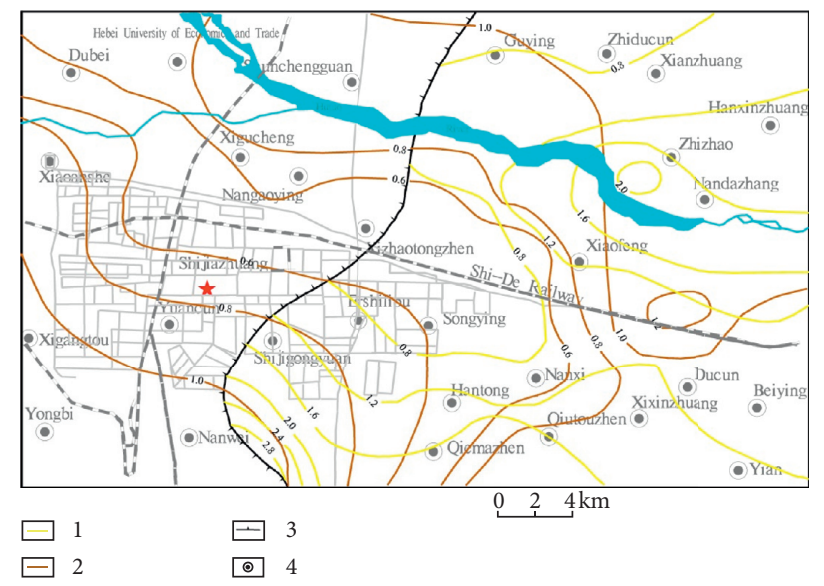

Figure 3: Strontium distribution in shallow and deep groundwater: (1) contour lines of strontium content in shallow water; (2) contour lines of strontium content in deep water; (3) boundary of the drainage area; and (4) villages.

3.3.2. Correlation between Strontium and Conventional Factors. Piper diagram is drawn based on the contents of major negative ions and cations (Figure 5) [30]. The figure suggests that the main hydrochemical types in the study area are $\mathrm{SO}_{4} \cdot \mathrm{Cl}-\mathrm{Ca} \cdot \mathrm{Mg}$ and $\mathrm{HCO}_{3}-\mathrm{Ca} \cdot \mathrm{Mg}$. Most of the groundwater in the study area is low salinity bicarbonate water, and $\mathrm{Mg}^{2+}, \mathrm{Ca}^{2+}$, and $\mathrm{HCO}_{3}{ }^{-}$are the most common ions. It can be seen from Figure 6 that $\mathrm{Sr}$ is positively correlated with TDS and TH. Lixiviation is the chief geochemistry action that controls strontium content $[31,32]$. 




(a)

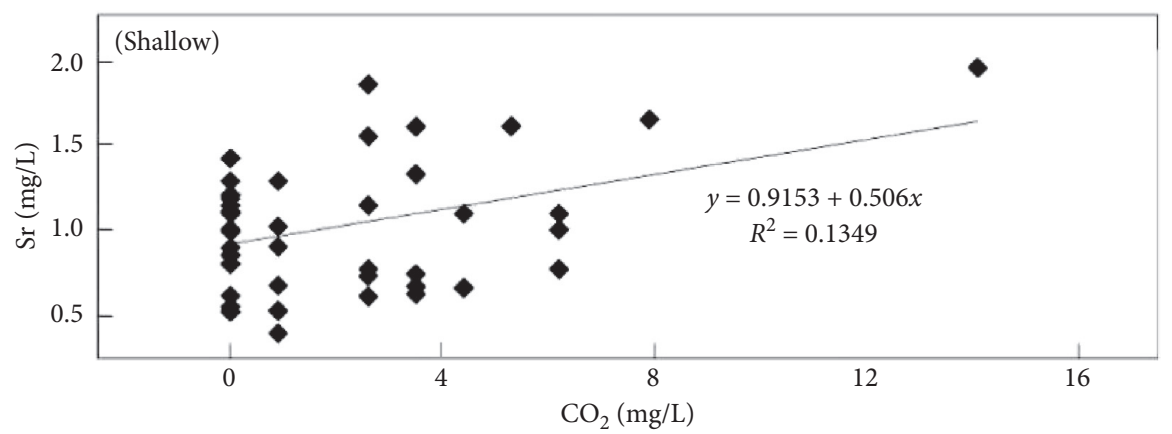

(b)

Figure 4: Relationship between strontium and free carbon dioxide in shallow and deep groundwater.

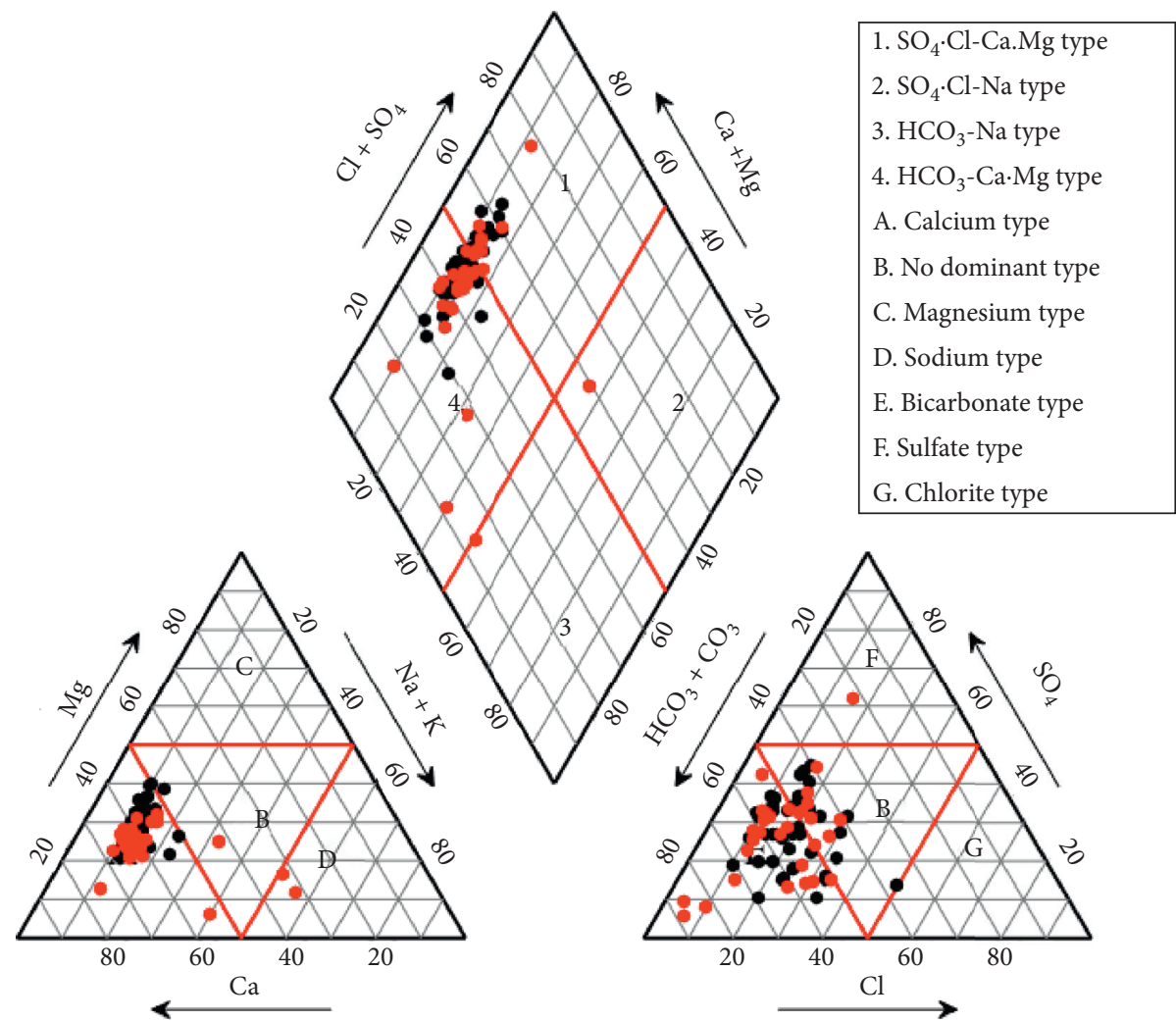

FIGURE 5: Piper diagram of groundwater samples. 




FIGURE 6: Relationship between groundwater strontium, TDS, and TH.

Studies have shown that mineral waters containing strontium are primarily of $\mathrm{HCO}_{3}$ type and secondarily of $\mathrm{HCO}_{3} \cdot \mathrm{SO}_{4}$ type [33]. Consequently, it can be speculated that the concentration of bicarbonate ions and sulfate ions in groundwater has a certain correlation with the concentration of strontium in groundwater. The relationship between strontium concentration and bicarbonate ion concentration in groundwater was plotted (Figure 7). As shown in the figure, the concentration of strontium in groundwater is positively correlated with the concentration of bicarbonate ions. It can be seen from Figure 8 that the concentration of strontium in groundwater is also positively correlated with the concentrations of $\mathrm{Ca}^{2+}$ and $\mathrm{Mg}^{2+}$, which indicates that the main components of the rocks that undergo leaching are carbonate minerals.

\subsection{Analysis of Strontium Enrichment}

3.4.1. Sources of Strontium. Strontium is a trace element in the lithosphere, but its abundance is the highest in the upper lithosphere. It is distributed widely with an average of $3.75 \times 10^{-4}$. The formation, enrichment, and distribution of Sr have certain regularity. They are affected by the geological background of the formation area, groundwater movement, and geochemical environment.

As a widely distributed trace element in nature, strontium is highly resolutive. Therefore, the content of strontium in natural water is slightly higher than that of other trace elements. In carbonate rock, gypsiferous clastic rock, and salt rock, minerals such as strontium carbonate and celestite are easily soluble in water. The rocks containing $\mathrm{Sr}$ are magmatic rocks, clastic rocks, and metamorphic rocks, which are formed by thermal metamorphism. These rocks are conducive to the dissolution of strontium. The strontium content in groundwater depends largely on its geochemical environment and the properties of strontium. During the weathering of rock, especially the decomposition of feldspar, the interaction between strontium salt and water rich in

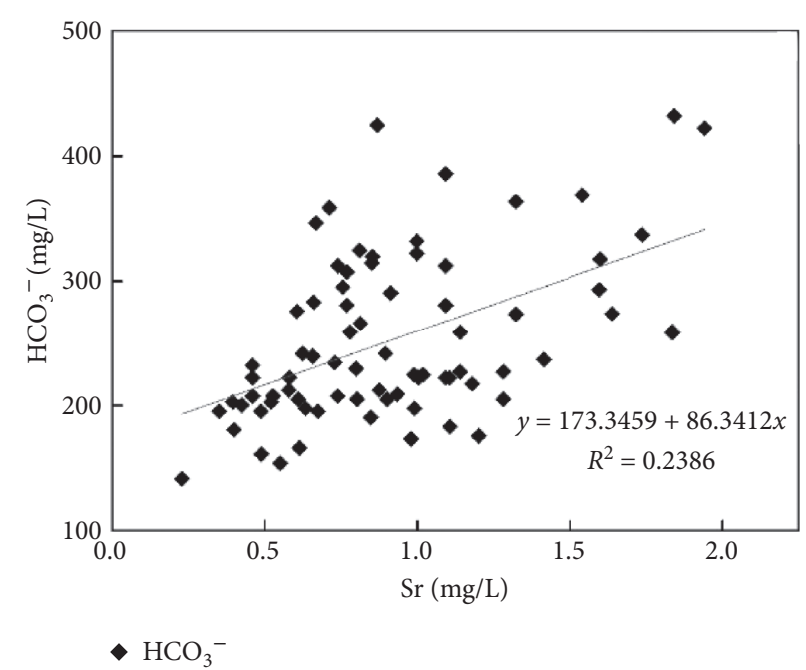

FIgURE 7: Relationship between groundwater strontium and bicarbonate.

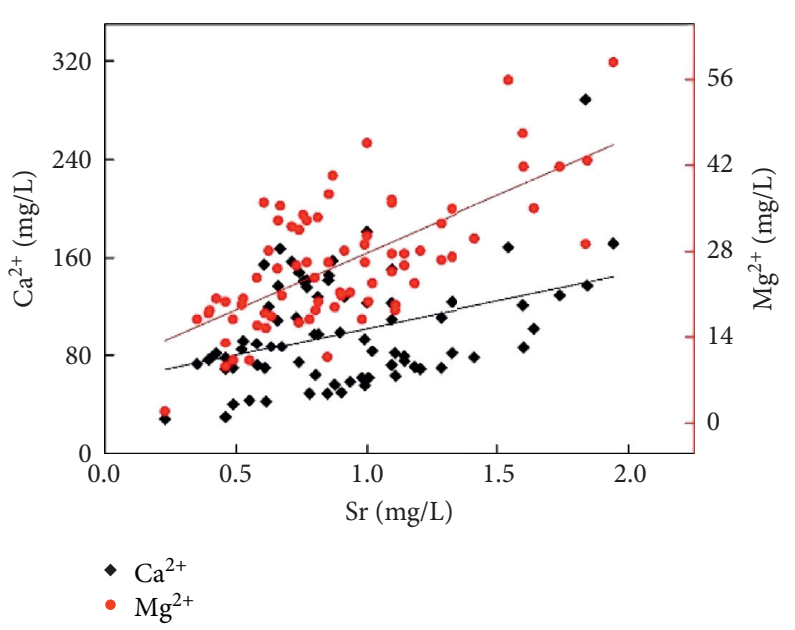

Figure 8: Relationship between strontium, calcium, and magnesium contents in groundwater.

carbon dioxide is beneficial to the precipitation of strontium. It dissolves in water and causes strontium enrichment.

The strontium content in groundwater is closely related to the geochemical environment such as the lithology of the aquiferous medium and strontium content. The content of strontium is the highest in carbonate rocks, followed by clastic strata, and also high in granite and granodiorite. The study area is located on the top and middle belt of Hutuo River alluvial fans. The stratigraphic distribution of the Hutuo River Basin upstream region mainly consists of the archaean group, fuping group, Wutai group, lower palaeozoic group, Hutuo group of gneiss and other metamorphic rocks, carbonate rock, clastic rock, upper palaeozoic, Cambrian Ordovician carbonate rocks, carboniferous Permian clastic rock, and granite, granite diorite vein, etc., as shown in Figure 9. There are many strontium-bearing minerals in the rocks, such as strontianite, which easily dissolve in water. The dissolution of strontium-bearing 


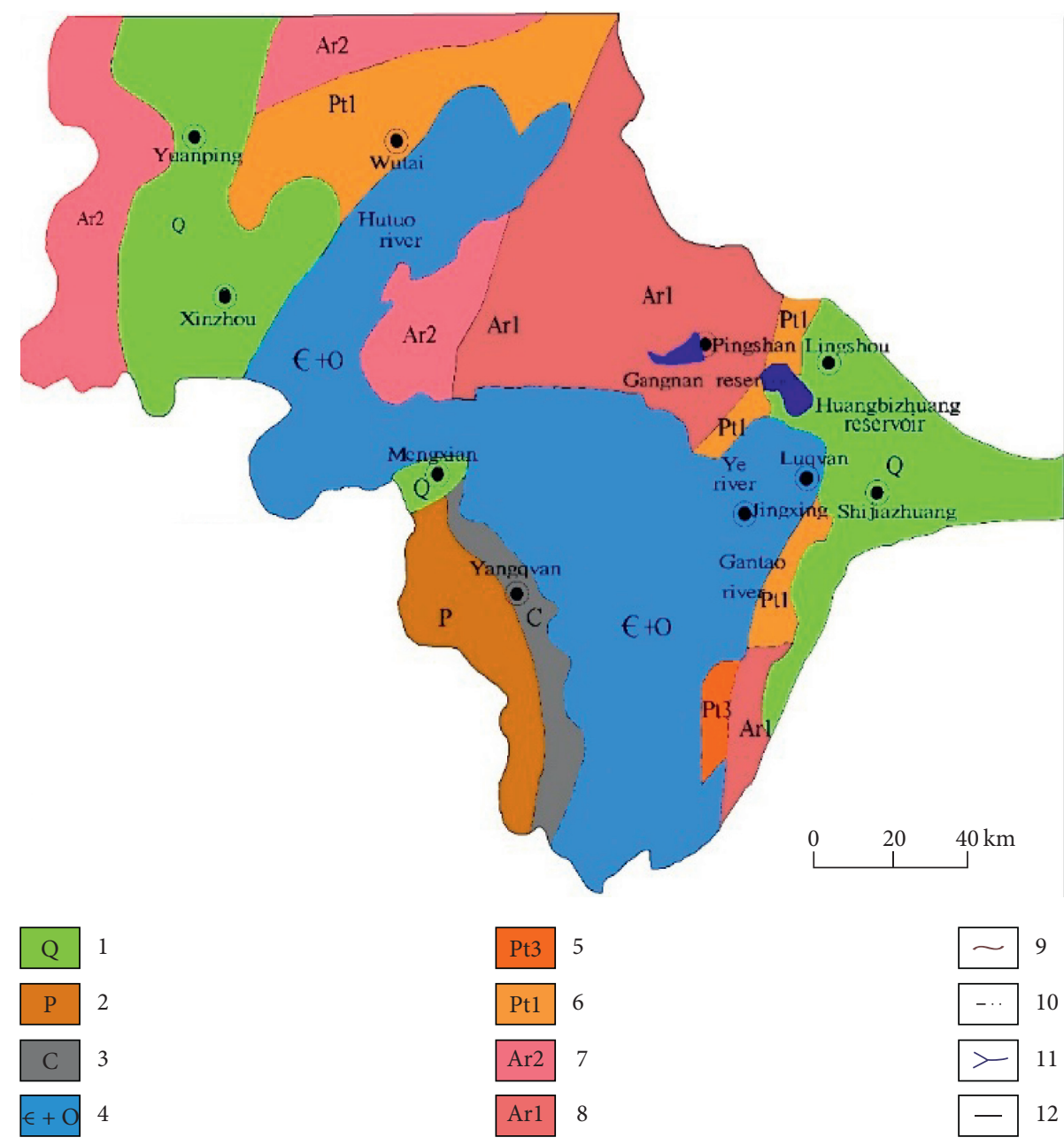

Figure 9: A geological sketch of the upstream region of the Hutuo River: (1) Quaternary system; (2) Permian system; (3) the carboniferous; (4) Cambrian Ordovician; (5) upper Paleozoic erathem; (6) lower Paleozoic erathem; (7) the Wutai group of the archaic kingdom; (8) Fuping group of the ancient kingdom; (9) basin boundary; (10) provincial boundary; (11) the rivers; and (12) stratigraphic boundary.

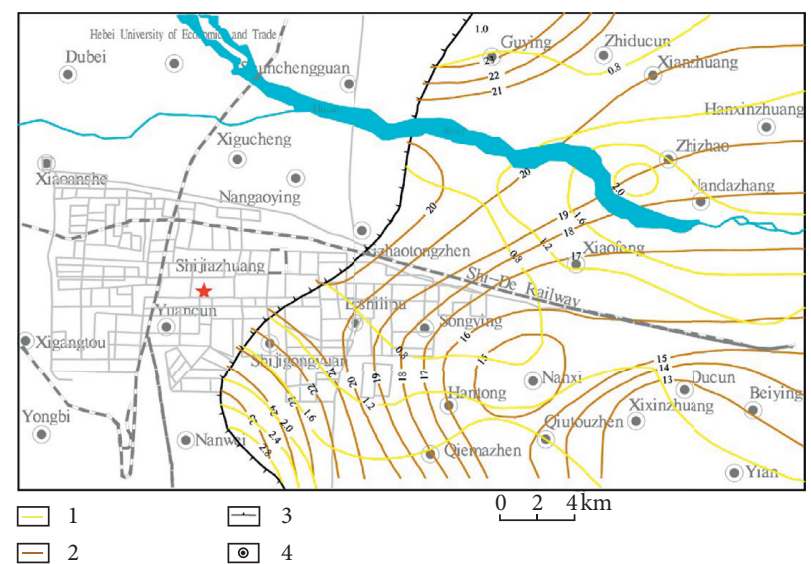

Figure 10: Contours and strontium distribution of the shallow groundwater level: (1) contour lines of strontium content in shallow water; (2) contour lines of water table in shallow water; (3) boundary of the drainage area; and (4) villages. 


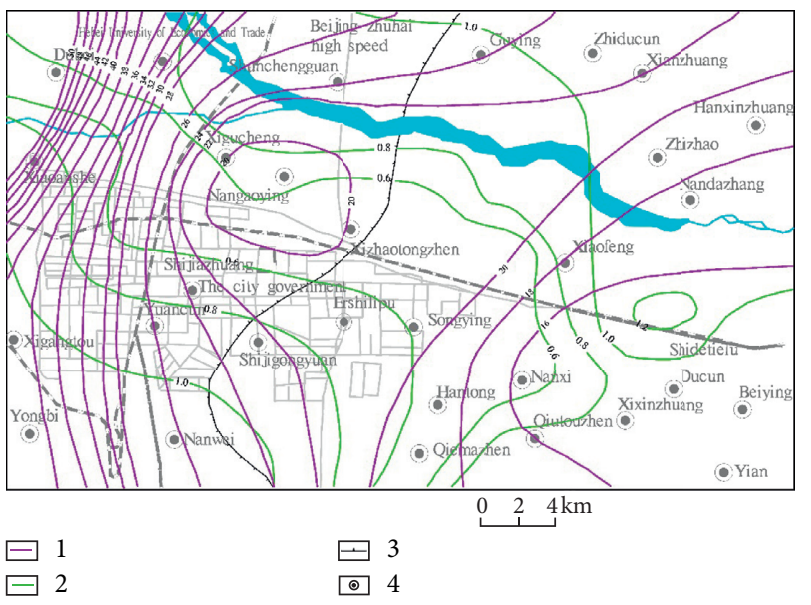

Figure 11: Contours and strontium distribution of the deep groundwater level: (1) contour lines of strontium content in deep water; (2) contour lines of water table in deep water; (3) boundary of the drainage area; and (4) villages.

minerals in these rocks is conducive to the enrichment of strontium in groundwater.

\subsubsection{Influence of the Ability of Groundwater Dissolution and} Erosion. The leaching, migration, and enrichment of strontium in groundwater are not only related to the content of strontium in the parent rock but also affected by water erosion. The erosive ability of water in nature mainly depends on the content of free carbon dioxide, and water rich in carbon dioxide is conducive to the dissolution of strontium. In shallow groundwater in the study area, the content of free carbon dioxide is mostly in the range of $0 \sim 14.4 \mathrm{mg} / \mathrm{L}$, while the content of strontium is in the range of $0.4 \sim 2.0 \mathrm{mg} / \mathrm{L}$. The content of free carbon dioxide in deep groundwater is typically in the range of $0 \sim 8.8 \mathrm{mg} / \mathrm{L}$, while the content of strontium is in the range of $0.5 \sim 1.2 \mathrm{mg} / \mathrm{L}$. The strontium content in shallow groundwater is generally higher than that in deep groundwater, which is related to the higher content of free carbon dioxide in shallow groundwater. This shows that the greater the content of free carbon dioxide in groundwater, the stronger the dissolution ability of strontium rock and the higher the content of strontium in mineral water. The carbon dioxide in the groundwater mainly comes from the fermentation of organic matter residues in soil and the respiration of plants. The carbon dioxide produced in the soil enters the groundwater. Thus, the content of free carbon dioxide in shallow groundwater is higher than that in deep groundwater.

3.4.3. Influence of Groundwater Circulation. The strontium enrichment of groundwater in the study area is closely related to groundwater circulation and runoff conditions. Due to the different permeabilities of diverse parts of the alluvialdiluvial fan and centralized exploitation of groundwater, there are obvious differences in groundwater runoff conditions and the content of strontium changes regularly. The strontium content is low in the axial part of the alluvial fan and the descending funnel. The strontium content is high in the areas with poor runoff conditions, while it is low in the areas with good runoff conditions.

The aquifer at the top and middle zone of the Hutuo River alluvial fan is thick, with good groundwater flow conditions and a strong water cycle. The strontium content gradually increases, from northwest to southeast along the groundwater flow, from the fan axis to the two sides of the Hutuo River alluvial fan. The strontium content presents a relatively low distribution zone in the region along the fan axis. The strontium content also shows a relatively low value in the influence range of the depression cone. This indicates that good groundwater runoff conditions and strong water circulation can inhibit the excessive enrichment of strontium, which is of great importance for the formation of strontium mineral water. The long-term concentrated groundwater exploitation has a certain influence on the strontium content (Figures 10 and 11).

\section{Conclusions}

By studying the distribution characteristics and causes of strontium enrichment in groundwater in the eastern area of Shijiazhuang, the following conclusions are obtained:

(1) The lithology of the Taihang Mountain area of the Hutuo River Valley is mainly carbonate rock and gneisses, followed by clastic rock, granite, granodiorite, etc. These rocks contain relatively high amounts of strontium. The strontium in groundwater is formed by the dissolution of strontiumbearing rocks, under the influence of specific conditions and environmental factors such as temperature and runoff.

(2) Strontium content is positively correlated with the contents of dissolved total solids, bicarbonate, calcium, magnesium, free carbon dioxide, and metasilicic acid in the study area. It is closely related to the erosion and dissolution ability of groundwater. The main chemical action is leaching. 
(3) The strontium content in the groundwater in most of the study area is more than $0.4 \mathrm{mg} / \mathrm{L}$. The enrichment and distribution of strontium in the groundwater are related to groundwater runoff conditions. Moreover, the strontium content is lower at the axial part of the alluvial-diluvial fan and the descending funnel. The area with poor runoff conditions is high in strontium content.

In summary, the results of this work help to identify the conditions and factors responsible for $\mathrm{Sr}$ enrichment in groundwater, which can be useful for the exploitation of Srcontaining mineral water. This study can provide a scientific basis for the development and protection of natural mineral water resources for drinking and the management planning of the relevant departments, to ensure that the abundant mineral water resources can be used rationally and continuously and to improve the drinking water quality in Shijiazhuang.

\section{Data Availability}

The data supporting the conclusions in this work are included in this manuscript. Other datasets generated and analyzed during the current work are available from the corresponding author on reasonable request.

\section{Conflicts of Interest}

The authors declare no conflicts of interest.

\section{Acknowledgments}

This work was supported by the Open Fund of the Key Laboratory of Subsurface Hydrology and Ecological Effects in the Arid Region of the Ministry of Education (300102299505) and the Natural Science Foundation of Education Department in Hebei Province (D2019403194).

\section{References}

[1] S. R. Taylor, and M. M. Scott, The Continental Crust: Its Composition and Evolution, 1985.

[2] F. Ehya, B. Shakouri, and M. Rafi, "Geology, mineralogy, and isotope ( $\mathrm{Sr}, \mathrm{S})$ geochemistry of the Likak celestite deposit, SW Iran," Carbonates and Evaporites, vol. 28, pp. 419-431, 2013.

[3] K. S. An, "Development status and main problems of drinking natural mineral water in China," North China Journal of Geology and Mineral Resources, vol. 4, pp. 341-346, 1994, in Chinese.

[4] Y. Gao, H. Qian, W. Ren, H. Wang, F. Liu, and F. Yang, "Hydrogeochemical characterization and quality assessment of groundwater based on integrated-weight water quality index in a concentrated urban area," Journal of Cleaner Production, vol. 260, 2020.

[5] Y. H. Zhou, P. Y. Li, L. L. Xue, Z. H. Dong, and D. Li, "Solute geochemistry and groundwater quality for drinking and irrigation purposes: a case study in Xinle city," North China Geochemistry, vol. 80, no. 4, 2020.

[6] S. H. Wang, L. Zhao, W. Huang et al., "Solvothermal synthesis of $\mathrm{CoO} / \mathrm{BiVO} 4 \mathrm{p}-\mathrm{n}$ heterojunction with micro-nano spherical structure for enhanced visible light photocatalytic activity towards degradation of tetracycline," Materials Research Bulletin, vol. 135, pp. 111161-111169, 2021.

[7] W. L. Shi, M. Y. Li, X. L. Huang et al., "Construction of $\mathrm{CuBi} 2 \mathrm{O} 4 / \mathrm{Bi} 2 \mathrm{MoO} 6$ p-n heterojunction with nanosheets-onmicrorods structure for improved photocatalytic activity towards broad-spectrum antibiotics degradation," Chemical Engineering Journal, vol. 394, pp. 125009-125018, 2020.

[8] X. Zhou, K. Zeng, R. R. Zhang, Y. Wang, and T. Q. Ma, "Study on adsorption distribution coefficient of $\mathrm{Sr}$ on silty clay," Nuclear Electronics and Detection Technology, vol. 33, no. 3, pp. 301-304, 2013.

[9] Y. Xie, Z. K. Shi, T. Wu, and D. Zhang, "Study on the influence of site groundwater characteristic factors on uranium and strontium adsorption," Chemical Research and Application, vol. 24, no. 11, pp. 1685-1690, 2012, in Chinese.

[10] K. Berninger and J. Pennanen, "Heavy metals in perch (Perca fluviatilis L.) from two acidified lakes in the Salpausselkä Esker area in Finland," Water, Air, and Soil Pollution, vol. 81, no. 34, pp. 283-294, 1995.

[11] S. Li, S. j. Ni, C. J. Zhang, M. G. Ding, and H. J. Wu, "Sorption kinetics of strontium in soil," Journal of Nuclear and Radiochemistry, vol. 29, no. 2, pp. 90-95, 2007.

[12] Y. E. Yang, Y. Li, W. Pan, Z. M. Wang, and S. W. Ni, "Migration of stable element Sr in soil columns," Atomic Energy Science and Technology, vol. 40, no. 3, pp. 292-296, 2006.

[13] L. Wu, S. J. Wang, and L. Li, "Adsorption characteristics of strontium on soil around a petrochemical wastewater reservoir in Xinjiang," Chemical Research and Application, vol. 3, pp. 12-16, 2012, in Chinese.

[14] J. Solecki, "Investigation of $85 \mathrm{Sr}$ adsorption in the presence of $\mathrm{Na}^{+}, \mathrm{K}^{+}$and $\mathrm{Cs}^{+}$on selected soils from different horizons," Journal of Radioanalytical and Nuclear Chemistry, vol. 268, no. 2, pp. 357-364, 2006.

[15] J. Solecki and S. Michalik, "Studies of 85Sr adsorption on grain fractions of soil," Journal of Radioanalytical and Nuclear Chemistry, vol. 267, no. 2, pp. 271-278, 2006.

[16] L. J. Huo, T. W. Qian, J. T. Hao, and D. Y. Zhao, "Sorption and retardation of strontium in saturated Chinese loess: experimental results and model analysis," Journal of Environmental Radioactivity, vol. 116, pp. 19-27, 2013.

[17] A. Boyer, P. Ning, D. Killey et al., "Strontium adsorption and desorption in wetlands: role of organic matter functional groups and environmental implications," Water Research, vol. 133, pp. 27-36, 2018.

[18] K. E. Pit'eva, M. A. Fortygina, and A. V. Mikheev, "Formation of the composition and quality of carbonate mineral water of the Elburgan water bearing complex (Essentuki Town)," Moscow University Geology Bulletin, vol. 62, pp. 277-285, 2007.

[19] M. Pennisi, R. Gonfiantini, S. Grassi, and P. Squarci, "The utilization of boron and strontium isotopes for the assessment of boron contamination of the Cecina river alluvial aquifer (central-western Tuscany, Italy)," Applied Geochemistry, vol. 21, no. 4, pp. 643-655, 2006.

[20] O. Alhassanieh, O. Mrad, and Z. Ajji, "Sorption and migration of $\mathrm{Cs}, \mathrm{Sr}$, and $\mathrm{Eu}$ in gypsum-groundwater system," Nukleonika, vol. 57, pp. 125-131, 2012.

[21] N. I. Ivanova, "Strontium distribution patterns in groundwater and aquifer host rocks in the southeastern part of the Severnaya Dvina artesian basin," Moscow University Geology Bulletin, vol. 69, no. 4, pp. 258-266, 2014.

[22] C. P. Petalas, "A preliminary assessment of hydrogeological features and selected anthropogenic impacts on an alluvial fan 
aquifer system in Greece," Environmental Earth Sciences, vol. 70, no. 1, pp. 439-452, 2013.

[23] Y. X. Wang, Z. L. Shen, and S. G. Moisevich, "Strontium hydrogeochemistry of thermal groundwaters from Baikal and Xinzhou," Science in China Series E: Technological Sciences, vol. 44, no. 1, pp. 138-143, 2001.

[24] Z. Rui, Y. G. Teng, and J. S. Wang, "Modeling migration of strontium in sand and gravel aquifer in the candidate VLLW disposal site," Journal of Radioanalytical and Nuclear Chemistry, vol. 281, no. 3, pp. 653-662, 2009.

[25] B. Christophe, M. V. Bocxstaele, E. Ponzevera, and C. R. Quétel, "Fit for purpose validated method for the determination of the strontium isotopic signature in mineral water samples by multi-collector inductively coupled plasma mass spectrometry," Spectrochimica Acta Part B: Atomic Spectroscopy, vol. 64, no. 3, pp. 229-234, 2009.

[26] K. Usuda, K. Kono, T. Dote et al., "Survey of strontium in mineral waters sold in Japan," Biological Trace Element Research, vol. 112, no. 1, pp. 77-86, 2006.

[27] B. Z. Yan, C. L. Xiao, X. J. Liang, R. C. Wei, and S. L. Wu, "Characteristics and genesis of mineral water from changbai mountain, Northeast China," Environmental Earth Sciences, vol. 73, no. 8, pp. 4819-4829, 2015.

[28] L. J. Liu, H. Z. Xu, Q. P. Cui, and J. Wang, "Evaluation of deep underground natural drinking mineral water field in eastern Shijiazhuang city," South-to-North Water Transfers and Water Science \& Technology, vol. 6, pp. 106-109, 2010, in Chinese.

[29] Y. H. Zhou, P. Y. Li, M. J. Chen, Z. H. Dong, and C. Y. Lu, "Groundwater quality for potable and irrigation uses and associated health risk in southern part of Gu'an county," North China Plain. Environ Geochem Health, vol. 43, no. 2, pp. 813-835, 2020.

[30] Y. H. Zhou, P. Y. Li, L. L. Xue, Z. H. Dong, and D. Li, "Solute geochemistry and groundwater quality for drinking and irrigation purposes: a case study in Xinle City," North China. Geochemistry, vol. 80, no. 4, 2020.

[31] Y. Gao, H. Qian, C. Huo, and J. Chen, "Assessing natural background levels in shallow groundwater in a large semiarid drainage basin," Journal of Hydrology, vol. 584, Article ID 124638, 2020.

[32] P. Y. Li, X. D. He, and W. Y. Guo, "Spatial groundwater quality and potential health risks due to nitrate ingestion through drinking water: a case study in Yan'an city on the Loess Plateau of northwest China," Human and Ecological Risk Assessment, vol. 25, no. 1-2, pp. 11-31, 2019.

[33] Y. H. Zhou, J. Ning, L. X. Li, Q. Long, and A. H. Wei, "Health risk assessment of groundwater in gaobeidian, North China: distribution, source, and chemical species of the main contaminants," Exposure and Health, vol. 12, no. 1-2, pp. 427-446, 2020 . 